\title{
Synthesis and Structural Characterization Studies on Solid Polymer Electrolyte System with Magnesium Triflate as Host Salt, EC as Plasticizer and MgO as Nanofiller
}

\author{
S. SAROJINI ${ }^{*}$ and C. ANJALAI \\ PG and Research Department of Physics, \\ Queen Mary's College (A), Chennai- 600004, India \\ saromkg@gmail.com
}

Received 23 October 2015 /Accepted 20 November 2015

\begin{abstract}
The present investigation describes the preparation, structural characterization studies on three different systems namely; system-I $\left((\mathrm{PMMA}+\mathrm{PVDF})_{\mathrm{y}}-\left(\mathrm{Mg}\left(\mathrm{CF}_{3} \mathrm{SO}_{3}\right)_{2}\right)_{1-\mathrm{y}}\right)$, where 1-y $=60$, $50,40,30$ and $20 \mathrm{~mol} \%$ respectively, System - II $\left((\mathrm{PMMA}+\mathrm{PVDF})_{\mathrm{y}}-\left(\mathrm{Mg}\left(\mathrm{CF}_{3} \mathrm{SO}_{3}\right)_{2}\right)_{1-\mathrm{y}}\right)_{\mathrm{z}}-(\mathrm{EC})_{1-\mathrm{z}}$, where $1-\mathrm{z}=25,20,15,10$ and $5 \mathrm{~mol} \%$ respectively and System-III ((PMMA + PVDF $)_{\mathrm{y}}$ $\left.\left.\left(\mathrm{Mg}\left(\mathrm{CF}_{3} \mathrm{SO}_{3}\right)_{2}\right)_{1-\mathrm{y}}\right)_{\mathrm{z}}-(\mathrm{EC})_{1-\mathrm{z}}\right)_{\mathrm{b}}-(\mathrm{MgO})_{1-\mathrm{b}}$, where 1-b $=20,15,10$ and $5 \mathrm{~mol} \%$ respectively and these systems were prepared by solution-casting technique. In system-III the $\mathrm{MgO}$ nanofiller of $32 \mathrm{~nm}$ size prepared by wet chemical sol-gel method is added to arrive at nanocomposite solid polymer electrolyte systems in four different compositions namely $1-b=20,15,10$ and $5 \mathrm{~mol} \%$ respectively. The synthesized $\mathrm{MgO}$ nanofiller size was confirmed by TEM study. Experimental techniques such as x-ray diffraction analysis, Fourier transform infrared spectroscopy (FTIR), differential scanning calorimetry (DSC) and surface morphological studies involving optical microscopy have been employed to explore their structural properties.
\end{abstract}

Keywords: Solution-casting method, Solid polymer electrolytes, Differential scanning calorimetry, Fourier transform infrared spectroscopy

\section{Introduction}

Polymer electrolytes find numerous applications in everyday usage as electrochemical devices such as polymer batteries, super capacitors, sensors and electro chromic windows. Solid polymer electrolytes exhibit a number of advantages, fast ionic transport in comparison with liquid electrolytes, chemically compatible with electrode materials, possessing good mechanical strength and flexibility as well as leak free ${ }^{1,2}$. A solid polymer electrolyte may include host salt which will dissociates into ions and dissolves in a polymer matrix leading to ionic conductivity. Numerous polymer materials with potential applications such as PMMA, PVDF, PEO, PEG etc. were found in literature by many researchers $^{3}$. In this study, PMMA (Poly(methyl methacrylate)) has been chosen as a host polymer, due to its outstanding chemico-physical properties ${ }^{4}$. 
Here our present effort has been focused mainly towards improving the ionic conductivity with appreciable mechanical stability in the case of a PMMA based solid polymer electrolyte at room temperature. Today, solid polymer blending is a versatile and widely used method for optimizing the cost-performance balance and increasing the range of potential applications, especially fluoropolymers such as PVDF which is often blended with amorphous polymers, among which poly (methyl methacrylate) (PMMA) has been the most studied compatible polymer owing to its low cost, optical properties, performance advantages and its nature of miscibility with other polymers in the melting state ${ }^{5,6}$. The studies of ionic conductivity in terms of $\mathrm{AC}$ impudence analysis were intended to the blended matrix of (PMMA $)_{x}-(P V D F)_{1-x}$ by our research group, wherein PMMA is the host polymer and PVDF is the co-polymer. The ac impedance study of the synthesized blended solid polymer electrolytes under four different compositions $(\mathrm{PMMA})_{\mathrm{x}}-(\mathrm{PVDF})_{1-\mathrm{x}}$, where $1-\mathrm{x}=95,90,85$ and $80 \mathrm{~mol} \%$ respectively revealed the best conduction composition as $(\mathrm{PMMA})_{50}-(\mathrm{PVDF})_{50}$ with the electrical conductivity value of $4.4496 \times 10^{-10} \mathrm{Scm}^{-1}$ at room temperature $(303 \mathrm{~K})$. The electrical conductivity of these blended polymer electrolytes could be improved with the addition of varying salt content and by adding suitable plasticizers and inert fillers. Magnesium electrochemistry at or near ambient temperature is rather undertaken by few researchers and a substantial research effort will be required in order to explore their possible use in electrochemical devices. The significant attention towards magnesium ion conducting polymer electrolyte system is due to important characteristics of the magnesium metal such as high charge density, considerably negative electrode potential, and high melting point $(922 \mathrm{~K})$, low cost, ease of handling, disposal and low toxicity ${ }^{7-9}$. The trifluoromethanesulfonate (triflate) ion, $\mathrm{CF}_{3} \mathrm{SO}_{3}{ }^{-}$, has proved to be an extremely important probe of ionic association in polymer salt complexes.

Hence in our present investigation, in order to achieve high ionic conductivity at ambient temperature, we planned to introduce Magnesium triflate as salt component in the blended polymer matrix of $(\mathrm{PMMA})_{50}-(\mathrm{PVDF})_{50}$. To improve the ionic conductivity at ambient temperature, a plasticizer may be added to the system. Among the plasticizers, in order to ensure strong dissociation, solvents having relatively high dielectric constants have been preferred, i.e., ethylene carbonate EC.

Nano-size particles are known to provide increase in ionic conductivity atleast an order of magnitude higher than micro-size particles and hence nano-size fillers are very interesting ones and are prove to improve ionic conductivity of polymer complex appreciably ${ }^{10}$. In this study, we intend to use $\mathrm{MgO}$ as nano filler. The advantages of incorporating the fillers are twofold. One is the enhancement in ionic conductivity at ambient temperatures and the other one is to improve the stability at the interface with electrodes.

The synthesis and characterization studies in terms of structural analysis were intended to the blended matrix of ((PMMA+PVDF $\left.)_{\mathrm{y}}-\left(\mathrm{Mg}\left(\mathrm{CF}_{3} \mathrm{SO}_{3}\right)_{2}\right)_{1-\mathrm{y}}\right), \quad\left((\mathrm{PMMA}+\mathrm{PVDF})_{\mathrm{y}}{ }^{-}\right.$ $\left.\left(\mathrm{Mg}\left(\mathrm{CF}_{3} \mathrm{SO}_{3}\right)_{2}\right)_{1-\mathrm{y}}\right)_{\mathrm{z}}-(\mathrm{EC})_{1-\mathrm{z}}$ and $\left(\left((\mathrm{PMMA}+\mathrm{PVDF})_{\mathrm{y}}-\left(\mathrm{Mg}\left(\mathrm{CF}_{3} \mathrm{SO}_{3}\right)_{2}\right)_{1-\mathrm{y}}\right)_{\mathrm{z}^{-}}(\mathrm{EC})_{1-\mathrm{z}}\right)_{\mathrm{b}}-(\mathrm{MgO})_{1-\mathrm{b}}$ in the present investigation.

\section{Experimental}

The method adopted for the synthesis of $(\mathrm{MgO})$ magnesium oxide for use as nanofiller in polymer electrolyte system is wet chemical reaction method or sol gel method. Chemicals used in this reaction method were of analytical purity and were used without further purification. The single phase $\mathrm{MgO}$ nano particles were synthesized by wet chemical technique, in which magnesium chloride $\left(\mathrm{MgCL}_{2} \cdot 2 \mathrm{H}_{2} \mathrm{O}-203.31 \mathrm{~g} / \mathrm{mol}\right)$ was used as main precursor material. 
For the synthesis of $0.1 \%$ of ethylenedinitrilo tetraacetic acid doped magnesium oxide, $1 \mathrm{M}$ solution of $\mathrm{NaOH}$ was prepared by dissolving $4 \mathrm{~g}$ of $\mathrm{NaOH}$ in $100 \mathrm{~mL}$ of double distilled water in a beaker. To that $0.1 \mathrm{~g}$ solution of EDTA $(0.29 \mathrm{~g})$ was added and the mixture was constantly stirred until a homogeneous solution of EDTA with $\mathrm{NaOH}$ was obtained. Then $1 \mathrm{~g}$ solution of $\mathrm{MgCl}_{2}(2.0331 \mathrm{~g})$ was added to this mixture and allowed to stir for $4 \mathrm{~h}$ and then the resultant mixture was centrifuged for about $60 \mathrm{~min}$ and washed with water several times to neutralize the $\mathrm{pH}$ of the solution.

The resultant product was filtered with a fine filter paper and the product thus obtained was kept in hot air oven at $333 \mathrm{~K}$ for $2 \mathrm{~h}$ and then heated in a Muffle furnace at $583 \mathrm{~K}$ for $3 \mathrm{~h}$. The resultant product was grounded in a mortar with a pestle into a grayish white powder and used for further characterization and analysis. The yield was good enough to carry on measurements and characterization. Figure 1 shows TEM micrograph of synthesized MgO nanoparticle. The micrograph reveal the cubic structure of $\mathrm{MgO}$ nanoparticles though they seem to be agglomerated, the dominantly cubic structures are roughly $32 \mathrm{~nm}$ in size ${ }^{11}$.

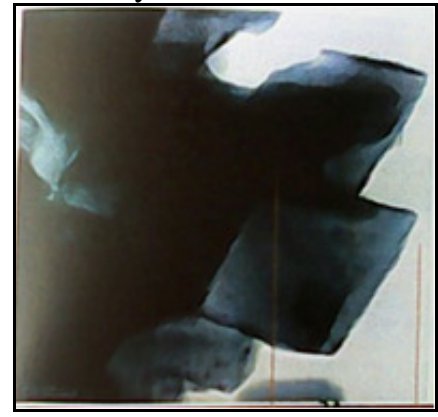

Figure 1. TEM Image of the EDTA doped MgO nanoparticle - $200 \mathrm{~nm}$ scale

The pure and blended polymer electrolytes were prepared by solution casting technique. Appropriate quantities of starting materials were taken in the weight ratio according to the stoichiometric compositions to arrive at the following systems

(i) Preparation of solid polymer electrolyte; System-I ((PMMA +PVDF $\left.)_{y}-\left(\mathrm{Mg}\left(\mathrm{CF}_{3} \mathrm{SO}_{3}\right)_{2}\right)_{1-\mathrm{y}}\right)$, where $1-\mathrm{y}=60,50,40,30$ and $20 \mathrm{~mol} \%$ respectively.

(ii) Preparation of solid polymer electrolyte; System-II $\left((\mathrm{PMMA}+\mathrm{PVDF})_{\mathrm{y}}-\left(\mathrm{Mg}\left(\mathrm{CF}_{3} \mathrm{SO}_{3}\right)_{2}\right)_{1-\mathrm{y}}\right)_{\mathrm{z}}-$ $(\mathrm{EC})_{1-\mathrm{z},}$, where $1-\mathrm{z}=25,20,15,10$ and $5 \mathrm{~mol} \%$ respectively.

(iii) Preparation of solid polymer electrolyte; System-III $\left(\left((\mathrm{PMMA}+\mathrm{PVDF})_{\mathrm{y}}-\left(\mathrm{Mg}\left(\mathrm{CF}_{3} \mathrm{SO}_{3}\right)_{2}\right)_{1-\mathrm{y}}\right)_{\mathrm{z}}\right.$ - $\left.(\mathrm{EC})_{1-\mathrm{z}}\right)_{\mathrm{b}}-(\mathrm{MgO})_{1-\mathrm{b}}$, where 1-b $=20,15,10$ and $5 \mathrm{~mol} \%$ respectively.

The raw materials poly(methyl methacrylate) (PMMA) with high molecular weight (99600 g/mol, 97\% purity), poly(vinylidene fluoride) (PVDF, 97\% purity) with high molecular weight $(275000 \mathrm{~g} / \mathrm{mol})$, Magnesium triflate $\left(\mathrm{Mg}\left(\mathrm{CF}_{3} \mathrm{SO}_{3}\right)_{2}, 97 \%\right.$ purity) with molecular weight $(32244 \mathrm{~g} / \mathrm{mol})$ respectively were purchased from sigma Aldrich, USA and used as such according to the stoichiometric compositions for preparation of System-1 ((PMMA + PVDF $)_{y}-\left(\mathrm{Mg}\left(\mathrm{CF}_{3} \mathrm{SO}_{3}\right)_{2}\right)_{1-\mathrm{y}}{ }^{\prime}$, where $1-\mathrm{y}=60,50,40,30$ and 20 mol\% respectively by solution casting technique. Raw materials were dissolved in solvent, dimethyl formamide (DMF) and the solution was subjected to magnetic stirring for approximately $6 \mathrm{~h}$ at room temperature till it becomes homogeneous. The homogeneous solution was poured into different flat petri dishes and dried in vacuum oven at $333 \mathrm{~K}$ at a pressure of 25 Torr for $24 \mathrm{~h}$ to evaporate the residual solvents. The films were transparent and light white colour, dry and free-standing in nature. 
Similarly for the preparation of System-II ((PMMA + PVDF) $\left.)_{\mathrm{y}}-\left(\mathrm{Mg}\left(\mathrm{CF}_{3} \mathrm{SO}_{3}\right)_{2}\right)_{1-\mathrm{y}}\right)_{\mathrm{z}}-(\mathrm{EC})_{1-\mathrm{z}}$, where $1-z=25,20,15,10$ and $5 \mathrm{~mol} \%$ respectively, along with the above mentioned raw materials, Ethylene carbonate (EC) (molecular weight - 8806 g/mol, Sigma Aldrich, USA) was added as plasticizer according to the stoichiometric compositions by solution casting method with dimethyl formamide (DMF) as solvent. In order to improve the ionic conductivity of the synthesized system-II, $\mathrm{MgO}$ with particle size $32 \mathrm{~nm}$ prepared by wet chemical method with EDTA as a catalyst is used as nanofiller. System-III (((PMMA + $\left.\left.\mathrm{PVDF})_{\mathrm{y}}-\left(\mathrm{Mg}\left(\mathrm{CF}_{3} \mathrm{SO}_{3}\right)_{2}\right)_{1-\mathrm{y}}\right)_{\mathrm{z}}-(\mathrm{EC})_{1-\mathrm{z}}\right)_{\mathrm{b}}-(\mathrm{MgO})_{1-\mathrm{b}}$, where $1-\mathrm{b}=25,15,10$ and $5 \mathrm{~mol} \%$ respectively represents the polymer electrolyte system with $\mathrm{EC}$ as plasticizer and $\mathrm{MgO}$ as nanofiller and different compositions of this system were by prepared by solution casting technique with dimethyl formamide (DMF) as solvent.

\section{Characterization studies}

\section{$X$-ray diffraction analysis}

The purity, structural property and constituent phases of the freshly prepared samples were subjected to powder x-ray diffraction analysis by JEOL (JDX - 8030) x-ray diffractrometer using $\mathrm{Cu}-\mathrm{K}_{\alpha}$ radiation $\left(\lambda=1.5406 \mathrm{~A}^{\circ}\right)$ in the $2 \theta$ range from $10^{\circ}$ to $80^{\circ}$.

\section{Fourier transform infrared spectroscopy (FTIR)}

The FTIR spectrum indicates the details of functional groups present in the synthesized sample and the spectra were recorded over the wave number range $4000-650 \mathrm{~cm}^{-1}$ using Agilent CARY 630 IR spectrometer.

\section{Differential scanning calorimetry (DSC)}

Differential scanning calorimetry (DSC) analysis of the present system was performed by using DSC Instrument MALVERN Metteler Toledo. The measurements were carried out in nitrogen atmosphere at a heating rate of $20{ }^{\circ} \mathrm{C} / \mathrm{min}$ in the temperature range of room temperature to $700 \mathrm{~K}$.

\section{Scanning electron microscopy (SEM)}

The synthesized polymer electrolyte systems were scanned with scanning electron microscope namely SEM HV VEGA 3 TESCAN with an accelerating voltage of 5-15 kV for surface morphological analysis.

\section{Results and Discussion}

$X$-ray diffraction analysis

Figure 2 includes XRD patterns obtained for the present system (( PMMA + PVDF $)_{50}$ $\left.\left.\left(\mathrm{Mg}\left(\mathrm{CF}_{3} \mathrm{SO}_{3}\right)_{2}\right)_{50}\right)_{80}-(\mathrm{EC})_{20}\right)_{\mathrm{b}}-(\mathrm{MgO})_{1-\mathrm{b}}$, where 1-b $=20,15,10$ and $5 \mathrm{~mol} \%$ respectively under investigation along with the best conducting compositions of blended polymer system, polymer electrolyte system with magnesium triflate salt and plasticized polymer electrolyte system with Ethylene carbonate as plasticizer namely (PMMA + PVDF $)_{50}$, $(\mathrm{PMMA}+\mathrm{PVDF})_{50}-\left(\mathrm{Mg}\left(\mathrm{CF}_{3} \mathrm{SO}_{3}\right)_{2}\right)_{50}$ and $\left((\mathrm{PMMA}+\mathrm{PVDF})_{50}-\left(\mathrm{Mg}\left(\mathrm{CF}_{3} \mathrm{SO}_{3}\right)_{2}\right)_{50}\right)_{80^{-}}(\mathrm{EC})_{20}$ respectively. The observed room temperature $\mathrm{x}$-ray diffraction patterns has been characterized by very less intense peaks which tends to suggest the formation of a relatively disordered type of material within these specimens. It is clear from the XRD pattern of $(\mathrm{PMMA})_{50}+(\mathrm{PVDF})_{50}$, (Figure 2) that blended sample exhibited the characteristics peaks at $2 \theta=20.84,26.8$ and $32.1^{\circ}$ with less intensity which corresponds to $\left[\begin{array}{lll}1 & 1 & 0\end{array}\right]$ and $\left[\begin{array}{lll}0 & 2 & 1\end{array}\right]$ reflection planes of $\mathrm{PVDF}^{12}$. 


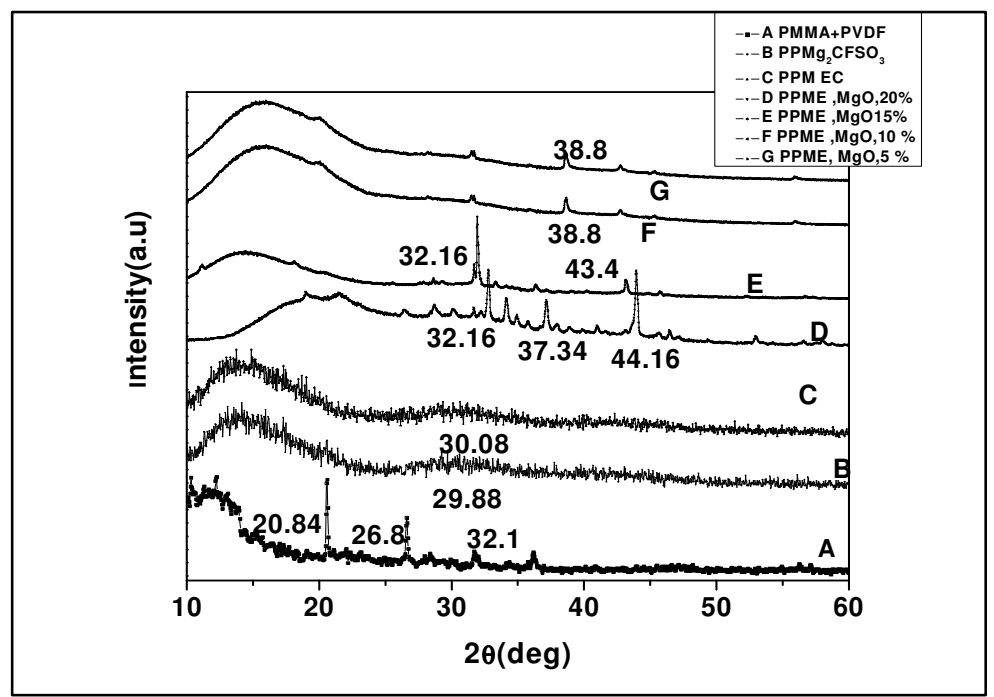

Figure 2 (A-F). Powder XRD patterns of solid polymer electrolyte system

Where A-(PMMA $)_{50}+(\mathrm{PVDF})_{50}$,

B-(PMMA + PVDF $)_{50}-\left(\mathrm{Mg}\left(\mathrm{CF}_{3} \mathrm{SO}_{3}\right)_{2}\right)_{50}$

C- $\left((\mathrm{PMMA}+\mathrm{PVDF})_{50}-\left(\mathrm{Mg}\left(\mathrm{CF}_{3} \mathrm{SO}_{3}\right)_{2}\right)_{50}\right)_{80}-(\mathrm{EC})_{20}$

D- $\left(\left((\mathrm{PMMA}+\mathrm{PVDF})_{50}-\left(\mathrm{Mg}\left(\mathrm{CF}_{3} \mathrm{SO}_{3}\right)_{2}\right)_{50}\right)_{80}-(\mathrm{EC})_{20}\right)_{80}-(\mathrm{MgO})_{20}$

E- $\left(\left((\mathrm{PMMA}+\mathrm{PVDF})_{50}-\left(\mathrm{Mg}\left(\mathrm{CF}_{3} \mathrm{SO}_{3}\right)_{2}\right)_{50}\right)_{80}-(\mathrm{EC})_{20}\right)_{85}-(\mathrm{MgO})_{15}$

$\left.\mathbf{F}-\left(\left((\mathrm{PMMA}+\mathrm{PVDF})_{50^{-}}\left(\mathrm{Mg}\left(\mathrm{CF}_{3} \mathrm{SO}_{3}\right)_{2}\right)_{50}\right)_{80}-(\mathrm{EC})_{20}\right)_{90}-\mathrm{MgO}\right)_{10}$,

G- $\left(\left((\mathrm{PMMA}+\mathrm{PVDF})_{50}-\left(\mathrm{Mg}\left(\mathrm{CF}_{3} \mathrm{SO}_{3}\right)_{2}\right)_{50}\right)_{80}-(\mathrm{EC})_{20}\right)_{95}-(\mathrm{MgO})_{5}$.

The diffraction pattern as shown in Figure 2 clearly indicates that the crystallinity in PMMA+PVDF system is further disturbed by the addition of $\mathrm{Mg}\left(\mathrm{CF}_{3} \mathrm{SO}_{3}\right)_{2}$. It is revealed that the blended polymer has undergone significant structural reorganisation while adding the plasticizer and $\mathrm{Mg}\left(\mathrm{CF}_{3} \mathrm{SO}_{3}\right)_{2}$ salt. The plasticized effect may induce significant interaction with Ethylene carbonate within the polymer matrix. The interaction between the PMMA, plasticizer and $\mathrm{Mg}_{2} \mathrm{CFSO}_{3}$ salt contributes a much lower crystallinity and enhances the structural disorderliness. The best conducting composition in (PMMA + PVDF $)_{50}$ shows less intense peaks at $2 \theta=20.56^{\circ}$ whereas the best conducting composition of ( $\mathrm{PVDF})_{50}-\left(\mathrm{Mg}\left(\mathrm{CF}_{3} \mathrm{SO}_{3}\right)_{2}\right)_{50}$ records very less intense peak at $2 \theta=30.68^{\circ}$ with complete amorphous background. The broader peaks and occurrence of new shoulder peak reveal that the amorphous nature of the film increases as a function of plasticizers concentration. The changes of the intensities of the broad characteristic peak, shoulder peak and intense peaks give strong evidence that EC mixture added into polymer matrices interact with the (PMMA+PVDF) blended polymer in the backbone and enhanced the amorphous nature of the plasticized polymer. The increase in the amorphous nature of plasticized polymer causes a reduction in the energy barrier for the segmental motion in polymer electrolyte. Therefore, higher ionic conductivity could be obtained at higher amorphous nature of polymer.

The best conducting composition in $\left((\mathrm{PMMA}+\mathrm{PVDF})_{50}-\left(\mathrm{Mg}\left(\mathrm{CF}_{3} \mathrm{SO}_{3}\right)_{2}\right)_{50}\right)_{80}-(\mathrm{EC})_{20}$ shows a feeble intense peak at $2 \theta=30.24^{\circ}$ with disordered background. However, with a further addition of nanoparticle $\mathrm{MgO}$, peaks corresponding to $2 \theta=32.16,37.14$ and $44.16^{\circ}$ occurs with less intensity for the $\mathrm{MgO}$ concentration ${ }^{13}$ of $20 \mathrm{~mol} \%$. The intensities of these 
peaks decrease when the content of $\mathrm{MgO}$ decreases suggesting the formation of disorderd nature. The XRD pattern denoted as (F) and (G) appears almost peak free and hence confirms the formation of amorphous nature because of the introduction of $\mathrm{MgO}$ nanofiller which may account for high ionic conduction. From literature study, it was shown that pure $\mathrm{MgO}$ nanoparticle shows peaks at $2 \theta=18.6,37.9,42.7$ and $66.7^{\circ}$ respectively. In the present XRD patterns, those peaks were not present indicating the complete interaction of $\mathrm{MgO}$ filler with the polymer matrix.

\section{Fourier transform infrared spectroscopy (FTIR)}

Figure 3 shows the spectra recorded for the best conducting compositions of blended polymer system, polymer electrolyte system with magnesium triflate salt and plasticized polymer electrolyte system with Ethylene carbonate as plasticizer namely $(\mathrm{PMMA}+\mathrm{PVDF})_{50}$, $\left((\mathrm{PMMA}+\mathrm{PVDF})_{50}-\left(\mathrm{Mg}\left(\mathrm{CF}_{3} \mathrm{SO}_{3}\right)_{2}\right)_{50}\right.$ and $\left((\mathrm{PMMA}+\mathrm{PVDF})_{50}-\left(\mathrm{Mg}\left(\mathrm{CF}_{3} \mathrm{SO}_{3}\right)_{2}\right)_{50}\right)_{80^{-}}(\mathrm{EC})_{20}$ respectively along with the four different compositions of system III (((PMMA + PVDF $)_{50}$ $\left.\left.\left(\mathrm{Mg}\left(\mathrm{CF}_{3} \mathrm{SO}_{3}\right)_{2}\right)_{50}\right)_{80}-(\mathrm{EC})_{20}\right)_{\mathrm{b}}-(\mathrm{MgO})_{1-\mathrm{b}}$, where 1-b = 20, 15, 10 and $5 \mathrm{~mol} \%$ respectively.

The characteristic peak at $3449 \mathrm{~cm}^{-1}$ indicates $\mathrm{OH}$ stretching, $2984 \mathrm{~cm}^{-1}$ indicates the presence of $\mathrm{C}-\mathrm{H}$ aliphatic stretching. For pure PMMA the frequency at $842 \mathrm{~cm}^{-1}$ is assigned to $\mathrm{C}-\mathrm{H}$ rocking vibrations. The frequencies at $2950 \mathrm{~cm}^{-1}$ and $1242 \mathrm{~cm}^{-1}$ are assigned to $\mathrm{CH}_{2}$ stretching and $\mathrm{O}-\mathrm{CH}_{2}$ deformation vibrations of pure PMMA. An absorption peak at $1718 \mathrm{~cm}^{-1}$ could be considered as $\mathrm{C}=\mathrm{O}$ stretching vibration due to $\mathrm{PMMA}^{14}$. Absorption at $1485 \mathrm{~cm}^{-1}$ indicates the presences of $\mathrm{CH}_{2}$ symmetric stretching vibration due to PVDF. The peak at $1144 \mathrm{~cm}^{-1}$ was believed to be affected by the symmetric stretching vibration of the $\mathrm{S}=\mathrm{O}$ bond affiliated with the $\mathrm{SO}^{3-}$ group ${ }^{13}$.

The absorption band at $900 \mathrm{~cm}^{-1}$ is assigned to be totally symmetric vibrations of per chlorate ions. C-F stretching vibrations were found to occur at $1200 \mathrm{~cm}^{-1}$ and $\mathrm{CF}_{2}$ stretching vibrations at $1050 \mathrm{~cm}^{-1}$ respectively. The absorption band at $881 \mathrm{~cm}^{-1}$ is the characteristic frequency of vinylidine compound ${ }^{15}$. An additional spectral feature observed at $984 \mathrm{~cm}^{-1}$ on addition of magnesium triflate into the polymer may be assigned to symmetric $\mathrm{SO}_{3}$ stretching of free triflate ion which emerges to be sensitive for the dissociation of the magnesium salt due to the feeble ion pairing between the cation $\left(\mathrm{Mg}^{2+}\right)$ and anion $\left(\mathrm{CF}_{3} \mathrm{SO}^{3-}\right)$ within the metal salt ${ }^{16}$. The peak present at $1141 \mathrm{~cm}^{-1}$ is found to show variation with the increase in nano filler $\mathrm{MgO}$ content. The broadened peak becomes a sharp absorption peak with the value shifted slightly with the decreasing content of $\mathrm{MgO}$. The same behavior is resulted for the peak at $1725 \mathrm{~cm}^{-1}$. For different composition of filler content, $1-\mathrm{b}=20,15,10$ and $5 \mathrm{~mol} \%$ respectively, variation in the case of an absorption peak occurs near about $1407 \mathrm{~cm}^{-1}$. For the composition, $5 \mathrm{~mol} \%$ of $\mathrm{MgO}$, there appears an absorption peak at $1407 \mathrm{~cm}^{-1}$. The characteristic peaks present due to different functional groups of the polymer system were found to be shifted towards the decreasing values on decreasing the content of nanofiller added. Thus, the above spectral features appear to confirm the appreciably good complexation within the present nanocompostie polymer electrolyte system which confirms a substantial changes in the network and likely to have an influence on the ionic conduction of the solid electrolyte system.

\section{Differential scanning calorimetry (DSC)}

DSC curves obtained for three different systems namely (PMMA+PVDF $)_{50^{-}}\left(\mathrm{Mg}\left(\mathrm{CF}_{3} \mathrm{SO}_{3}\right)_{2}\right)_{50}$, $\left((\mathrm{PMMA}+\mathrm{PVDF})_{50}-\left(\mathrm{Mg}\left(\mathrm{CF}_{3} \mathrm{SO}_{3}\right)_{2}\right)_{50}\right)_{80}-(\mathrm{EC})_{20}$ and $\left(\left((\mathrm{PMMA}+\mathrm{PVDF})_{50}-\left(\mathrm{Mg}\left(\mathrm{CF}_{3} \mathrm{SO}_{3}\right)_{2}\right)_{50}\right)_{80^{-}}\right.$ $\left.\left.(\mathrm{EC})_{50}\right)_{20}\right)_{90}-(\mathrm{MgO})_{10}$ respectively were shown in Figure 4 as $\mathrm{A}, \mathrm{B}$ and $\mathrm{C}$ respectively. For pure PVDF, the glass transition temperature would be observed at $239 \mathrm{~K}$ whereas for pure PMMA, the same could be around ${ }^{17-18} 372 \mathrm{~K}$. In the case of the system with the addition of 
$\mathrm{Mg}\left(\mathrm{CF}_{3} \mathrm{SO}_{3}\right)_{2}$ as host salt to the blended matrix namely (PMMA+PVDF $)_{50^{-}}\left(\mathrm{Mg}\left(\mathrm{CF}_{3} \mathrm{SO}_{3}\right)_{2}\right)_{50}$, the peak at $649 \mathrm{~K}$ represents the melting temperature of the synthesized sample with sharp exothermic peak along with the shoulder at $567 \mathrm{~K}$, which may be attributed as due to melting point of intermediate phase formed. The peak at $381 \mathrm{~K}$ could be regarded as the glass transition temperature of the synthesized blended sample. It was inferred from the DSC curves that the above mentioned peaks were getting shifted towards lesser values as indicated in the figure as A, B and C. For the curve denoted as ' $\mathrm{C}$ ' which represents the best conducting composition of the system with the addition of nanofiller, $\mathrm{MgO}$, variations in the values of the peaks were noted. Also, one new exothermic peak is observed at $361 \mathrm{~K}$ which may be attributed due to the probable interaction between the filler particles and polymer host resulting in a indicating the reorganization of the polymer.

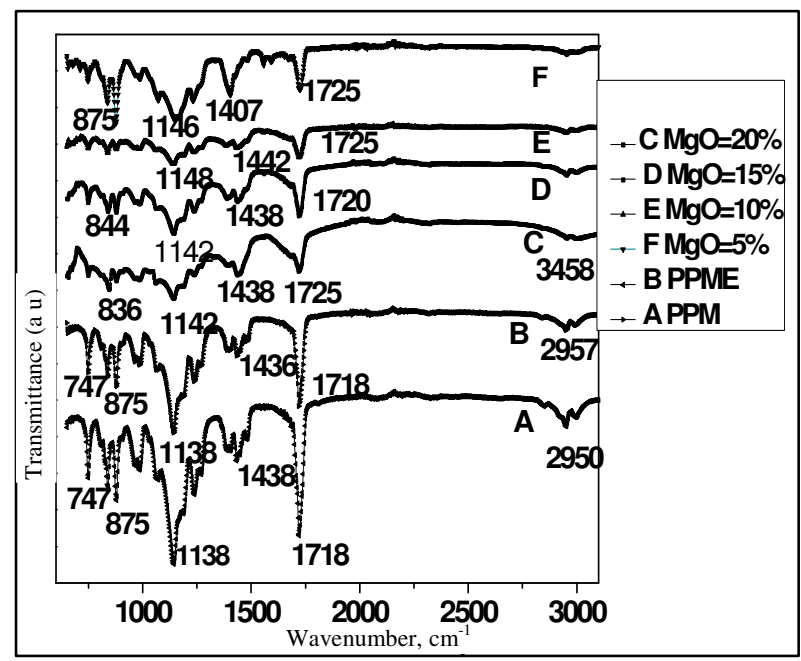

Figure 3. FTIR spectra observed in solid polymer electrolyte system

A - $(\text { PMMA + PVDF })_{50}$

B - $\left((\mathrm{PMMA}+\mathrm{PVDF})_{50}-\left(\mathrm{Mg}\left(\mathrm{CF}_{3} \mathrm{SO}_{3}\right)_{2}\right)_{50}\right)_{80}$

C - $\left((\mathrm{PMMA}+\mathrm{PVDF})_{50}-\left(\mathrm{Mg}\left(\mathrm{CF}_{3} \mathrm{SO}_{3}\right)_{2}\right)_{50}\right)_{80}-(\mathrm{EC})_{20}$

D - $\left(\left((\mathrm{PMMA}+\mathrm{PVDF})_{50}-\left(\mathrm{Mg}\left(\mathrm{CF}_{3} \mathrm{SO}_{3}\right)_{2}\right)_{50}\right)_{80}-(\mathrm{EC})_{20}\right)_{80}-(\mathrm{MgO})_{20}$

$\mathbf{E}-\left(\left((\mathrm{PMMA}+\mathrm{PVDF})_{50}-\left(\mathrm{Mg}\left(\mathrm{CF}_{3} \mathrm{SO}_{3}\right)_{2}\right)_{50}\right)_{80}-(\mathrm{EC})_{20}\right)_{85}-(\mathrm{MgO})_{15}$

$\mathbf{F}-\left(\left((\mathrm{PMMA}+\mathrm{PVDF})_{50^{-}}\left(\mathrm{Mg}\left(\mathrm{CF}_{3} \mathrm{SO}_{3}\right)_{2}\right)_{50}\right)_{80}-(\mathrm{EC})_{20}\right)_{90}-(\mathrm{MgO})_{10}$

$\mathbf{G}-\left(\left((\mathrm{PMMA}+\mathrm{PVDF})_{50}-\left(\mathrm{Mg}\left(\mathrm{CF}_{3} \mathrm{SO}_{3}\right)_{2}\right)_{50}\right)_{80}-(\mathrm{EC})_{20}\right)_{95}-(\mathrm{MgO})_{5}$

\section{Scanning electron microscopy (SEM)}

SEM micrograph obtained for the synthesized solid polymer electrolyte systems namely $(\mathrm{PMMA}+\mathrm{PVDF})_{50}-\left(\mathrm{Mg}_{2} \mathrm{CFSO}_{3}\right)_{50}$, ( $\left.\left.\mathrm{PMMA}+\mathrm{PVDF}\right)_{50}-\left(\mathrm{Mg}\left(\mathrm{CF}_{3} \mathrm{SO}_{3}\right)_{2}\right)_{50}\right)_{80}-(\mathrm{EC})_{20}$ and $(((\mathrm{PMMA}$ $\left.\left.+\mathrm{PVDF})_{50}-\left(\mathrm{Mg}\left(\mathrm{CF}_{3} \mathrm{SO}_{3}\right)_{2}\right)_{50}\right)_{80}-(\mathrm{EC})_{20}\right)_{90}-(\mathrm{MgO})_{10}$ respectively were shown in Figure 5 with as $\mathrm{a}, \mathrm{b}$ and $\mathrm{c}$ respectively. Figure 5(a) shows a non-uniform nature of grains with rod like structure in the background. The calculated average grain size could be taken as $120 \mathrm{~nm}$.

Figure 5(b) which accounts for the polymer system with $\mathrm{Mg}_{2} \mathrm{CFSO}_{3}$ host salt with added plasticizer shows clear disordered background with more space for movement. Here, a grain appears more legibly as cluster with diameter of $350 \mathrm{~nm}$. Figure 5(c) shows unevenly distributed grains in the form of clusters with voids facilitating movement of ions which in turn provides high conducting pathways of this best conducting composition with $10 \mathrm{~mol} \%$ 
nanofiller, $\mathrm{MgO}$. The clusters look like a flower like arrangement in many places representing the agglomeration of particles due to the interaction of polymer matrix with the filler. Mostly all the grains were fairly regular with most of the grains looks like a petal. A tiny grain is taken for the calculation of grain size under $1 \mu \mathrm{m}$ scale and the average size calculated was $100 \mathrm{~nm}$ diameters.

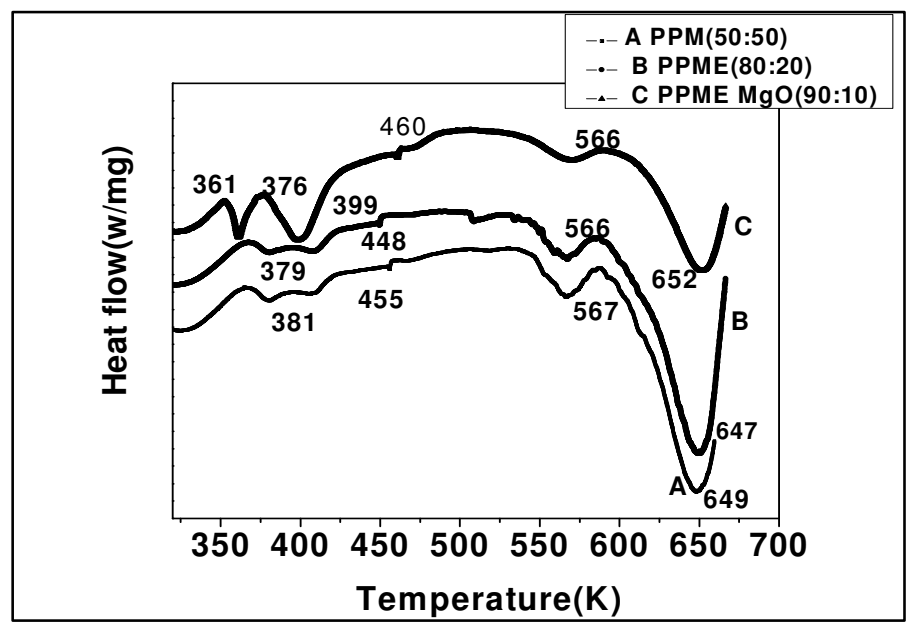

Figure 4. The DSC curves obtained for the best composition of the synthesized systems namely A- $(\mathrm{PMMA}+\mathrm{PVDF})_{50^{-}}\left(\mathrm{Mg}\left(\mathrm{CF}_{3} \mathrm{SO}_{3}\right)_{2}\right)_{50}$,

B- $\left((\mathrm{PMMA}+\mathrm{PVDF})_{50}-\left(\mathrm{Mg}\left(\mathrm{CF}_{3} \mathrm{SO}_{3}\right)_{2}\right)_{50}\right)_{80}-(\mathrm{EC})_{20}$

$\mathrm{C}-\left(\left((\mathrm{PMMA}+\mathrm{PVDF})_{50}-\left(\mathrm{Mg}\left(\mathrm{CF}_{3} \mathrm{SO}_{3}\right)_{2}\right)_{50}\right)_{80}-(\mathrm{EC})_{20}\right)_{90}-(\mathrm{MgO})_{10}$

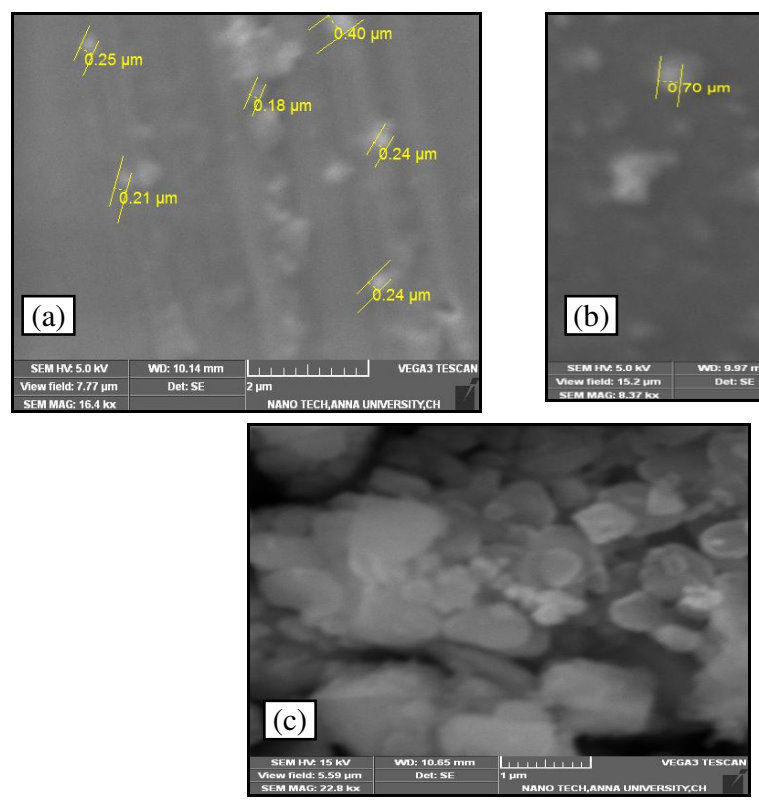

Figure 5. SEM images of (a) (PMMA+PVDF $)_{50}-\left(\mathrm{Mg}\left(\mathrm{CF}_{3} \mathrm{SO}_{3}\right)_{2}\right)_{50}$, (b) $\left((\mathrm{PMMA}+\mathrm{PVDF})_{50^{-}}\right.$ $\left.\left(\mathrm{Mg}\left(\mathrm{CF}_{3} \mathrm{SO}_{3}\right)_{2}\right)_{50}\right)_{80}-(\mathrm{EC})_{20},(\mathrm{c})\left(\left((\mathrm{PMMA}+\mathrm{PVDF})_{50^{-}}\left(\mathrm{Mg}\left(\mathrm{CF}_{3} \mathrm{SO}_{3}\right)_{2}\right)_{50}\right)_{80^{-}}(\mathrm{EC})_{20}\right)_{90^{-}}(\mathrm{MgO})_{10}$ 


\section{Conclusion}

The synthesis and structural studies of three different systems I, II and III by solution casting technique indicates the fact that observed structural analysis throws light on the structural aspects of the prepared solid polymer electrolyte systems in terms of XRD, FTIR, DSC and SEM characterization studies and interpretation of their results conforms the complete miscibility of the raw materials and their enhancement towards the amorphous nature as indicated in XRD analysis.

\section{Acknowledgement}

The authors would like to thank centre for instrumentation facility(CIF), FIST, Queen Mary's College (A), Chennai.4.for FTIR anaysis, Centre for NanoScience and Nanotechnology, Anna university, Chennai-25, for DSC and SEM analysis and Department of Nuclear Physics, University of Madras, Chennai-25, for XRD characterization studies. One of the authors acknowledges UGC, New Delhi for the financial support received in the form of a minor research project (Dr. S. Sarojini, No.F MRP-5226/14 (SERO/UGC) in Dept. of Physics, Queen Mary's College (A), Chennai-4, India.

\section{References}

1. Manuel Stephan A, Eur Poly J., 2006, 42(1), 21-42;

DOI:10.1016/j.eurpolymj.2005.09.017

2. Amrtha Bhide and Hariharan K, Eur Poly J., 2007, 43(10), 4253-4270;

DOI:10.1016/j.eurpolymj.2007.07.038

3. Yahya M Z A and Arof AK, Eur Poly J., 2002, 38(6), 1191-1197;

DOI:10.1016/S0014-3057(01)00290-7

4. Jose L Garcia, Kurt W Koelling and Robert R Seighi, Polymer, 1998, 39(8-9), 15591567; DOI:10.1016/S0032-3861(97)00498-9

5. Moussaif N, Pagnoulle C, Riga J and Jerome R, Polymer, 2000, 41(9), 3391-3394; DOI:10.1016/S0032-3861(99)00498-X

6. Isabella Nicotera, Luigi Coppola, Cesare Oliviero, Marco Castriota and Enzo Cazzanelli, Solid State Ionics, 2006, 177(5-6), 581-588; DOI:10.1016/j.ssi.2005.12.028

7. Ammakutti N, Shyly P M and Sahaya S X, Int J Sci Tech Manage., 2015, 4(1), 171-180.

8. Ravindran D and Vickraman P, Int J Sci Engg Appl (IJSEA), 2012, 1(1), 72-74; DOI:10.7753/IJSEA0101.1012

9. Zainol N H, Osman Z, Othman L and Md. Isa K B, Adv Mater Res., 2013, 686, 137 144; DOI:10.4028/www.scientific.net/AMR.686.137

10. Anji Reddy Polu, RJPBCS, 2014, 5(1), 953-961;

11. Mastuli M S, Kamarulzaman N, Nawawi M A, Mahat A M, Rusdi R and Kamarudin N, Nanoscale Research Letters, 2014, 9,134; DOI: 10.1186/1556-276X-9-134

12. Amudha S, Austin Suthanthiraraj S and Maruthamuthu P, Chem Sci Trans., 2013, 2(3), 955-963; DOI:10.7598/cst2013.450

13. Arulsankar A, Kulasekarapandian K and Jeya S, Jayanthi S and Sundaresan B, IJIRSET, 2013, 2, 4883-4890.

14. Austin Suthanthiraraj S and Kumaravadivel M, Ionics, 2012, 18(4), 385-394; DOI:10.1007/s11581-011-0637-0

15. Morita M, Araki F, Yoshimoto N, Ishikawa M and Tsutsumi H, Solid State Ionics, 2000, 136-137, 1167-1173; DOI:10.1016/S0167-2738(00)00613-5

16. Ammakutti N@ Sridevi, Karuppasamy. K, Balakumar. S and Sahaya Shajan X, Chem Sci Trans., 2012, 1(2), 311-316; DOI:10.7598/cst2012.198

17. Hronsky V and Murın J, Acta Physica Slovaca, 2002, 52(2), 91-100.

18. Gaur M S, Prashant Shukla, Tiwari R K, Anju Tanwar and Singh S P, Indian J Pure Applied Physics, 2008, 46, 535-539. 